\title{
Positive transfer of familiarization training to recognition performance: Effects of stimulus complexity and association value
}

RICHARD H. PRICE AND ROBERT HILL, PSYCHOLOGY DEPARTMENT, INDIANA UNIVERSITY, Bloomington, Ind. 47401

Effects of complexity and association value of random shapes on the amount of transfer from stimulus familiarization training to a later recognition task were examined. Familiarization training resulted in strong positive transfer effects to later recognition performance. Increases in stimulus complexity were associated with increases in recognition performance only when familiarization training was administered. It was suggested that increases in stimulus complexity provide more usable stimulus information for recognition but that such information is only effectively utilized by $S$ for recognition when familiarization training is provided.

Experimental procedures in which $\mathrm{S}$ is exposed to a set of visual stimuli which are later used in a recognition task usually yield positive transfer effects. A recent review of perceptual learning and recognition (Tighe \& Tighe, 1966) suggests that considerable controversy still exists concerning the mechanisms underlying the positive transfer effect. Facilitation of recognition performance following familiarization procedures has been accounted for by both "differentiation" (Gibson \& Gibson, 1955) and "mediation" explanations (Goss, 1955). The differentiation position suggests that the facilitating effect of stimulus familiarization may be due to an increase in S's ability to distinguish sources of physical variation present in stimuli. Increases in stimulus complexity (Garner, 1962) will increase discriminability in this manner. Mediation approaches suggest a verbal labeling process which is assumed to account for positive transfer effects. Since the association value of a visual stimulus should affect the probability with which $S$ produces associations to that stimulus during stimulus familiarization, it should also affect later recognition of that stimulus.

Visual stimuli are available which vary in both complexity and association value (Vanderplas \& Garvin, 1959). Thus it is possible to examine the effects of these two variables upon the amount of transfer due to stimulus familiarization. The purpose of the present experiment was to examine these effects when (a) $S$ had no opportunity to familiarize himself with the stimuli prior to learning and recognition tasks, and when (b) a large number of familiarization trials with the entire stimulus set was presented.

Method. Ninety-six volunteer university students served as Ss. Eight Ss were randomly assigned to each of the 12 experimental conditions generated by the 2 (familiarization) by 3 (complexity) by 2 (association value) experimental design.

Photocopies of random shapes (Vanderplas \& Garvin, 1959) varying in complexity $(6,12$, and 24 tums) and association value (high and low) were employed. A set of 22 shapes was selected for each of the three complexity levels consisting of 11 high and 11 low association value stimuli. Associative value was in terms of the per cent of Ss making an associative response to a given stimulus. The means and standard deviations for high association value sets for the 6-, 12-, and 24-tum stimuli, respectively, were: $M=44.36, S D=$ $5.27 ; M=44.36, S D=3.92 ; M=44.36, S D=4.67$. Similarly the means and standard deviations for the low association value stimuli for the $6-12-$, and 24turn stimuli, respectively, were: $M=32.00, S D=4.74 ; M=32.00, S D=$ $5.00 ; \mathrm{M}=32.00, \mathrm{SD}=2.82$. Each of the six sets of 11 stimuli varying in complexity and association value and presented in fixed random order composed a learning set. Within the total recognition set for a particular level of complexity, each of the 22 stimuli in the recognition set was repeated five times. Thus each recognition set consisted of 110 stimuli in blocks of 22 with the stimuli in each block having a different fixed random order.

In the familiarization task, Ss were told that they would view 22 shapes for $3 \mathrm{sec}$ each and that each of the shapes would be repeated a number of times. Ss were told that careful observation of the shapes during the familiarization task should facilitate performance in subsequent learning and recognition tasks. The Ss were presented with the 22 shapes for 3 sec each, and 10 blocks of 22 stimuli were presented for a total of 220 familiarization trials. In the learning task, Ss were informed that they would view 11 shapes for $3 \mathrm{sec}$ each, and that these were the stimuli that they would be required to recognize from a larger set of shapes in the final recognition task. The Ss controlled their own stimulus presentation, and their viewing rate was paced by tape-recorded counting of learning trials at $3 \mathrm{sec}$ intervals.

After the completion of the learning task, Ss were presented with a $3 \mathrm{~min}$ interpolated number cancellation task. In the final recognition task, Ss were instructed that stimuli would be rated as "seen before," or "not seen before" during the learning task. The Ss were instructed in the use of a recognition rating scale which took the following form: (1) seen before, positive;(2) seen before, fairly sure; (3) seen before, guess; (4) not seen before, guess; (5) not seen before, fairly sure; (6) not seen before, positive. The rating method of obtaining variance in S's criterion of acceptance of a stimulus as "seen before" or "not seen before" has been described by Egan (1958) and Pollack, Norman, \& Galanter (1964) as an efficient means of obtaining variation in Ss criterion. The Ss were instructed that exactly half of the stimuli in the recognition set had been "seen before" in the learning task. It was also emphasized that all six ratings should be used in the recognition task, and that extreme confidence ratings (1s and 6s) should be used sparingly since naive Ss often do not adopt a stringent enough criterion for the use of extreme ratings (Egan, 1958). Ss were then presented with the $1105-\mathrm{sec}$ recognition trials.

Results and Discussion. Recognition performance was evaluated by computing for each $S$ the proportion of the total area under the empirically derived operating characteristic. This measure $p(A)$, is formally related to the proportion of correct responses in the forced choice, single interval experiment and does not require strong assumptions concerning the nature of distribution of underlying recognition events (Green \& Swets, 1966). Performance scores were analyzed using a three-way analysis of variance (familiarization by stimulus complexity by association value). Results are shown in Fig. 1.

A significant main effect was obtained for familiarization training $(F=69.07, \mathrm{df}=1 / 84, p<.001)$. This rather large effect indicates that familiarization training does in fact produce positive transfer to the recognition task. The interaction between stimulus

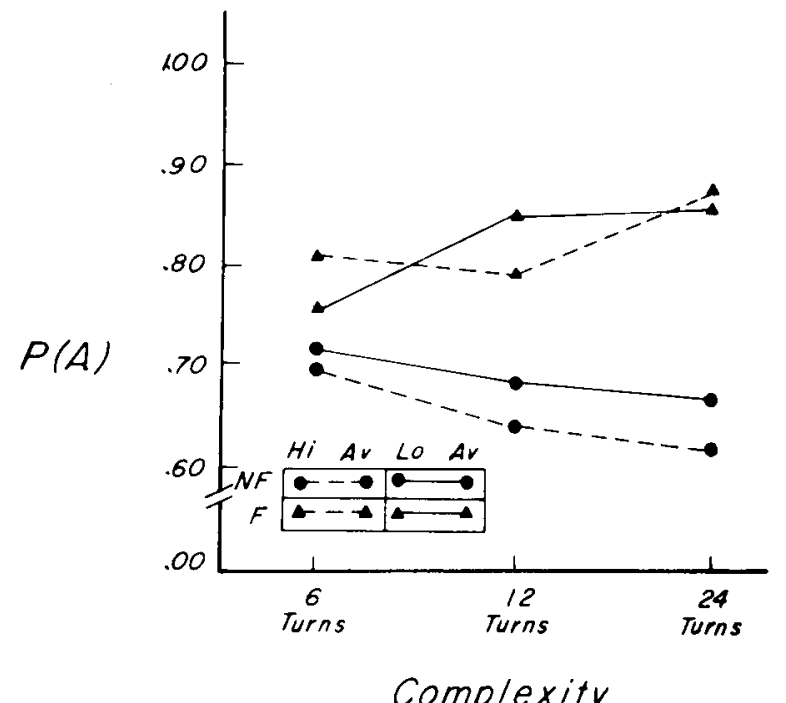

Fig. 1. Effects of stimulus complexity $(6,12,24$ turns) and familiarization training (F) vs no familiarization (NF) training on p(A). 
complexity and familiarization training conditions was also significant $(F=5.51, \mathrm{df}=2 / 84, \mathrm{p}<.01)$. Examination of Fig. 1 suggests that increases in stimulus complexity may either improve or decrease recognition performance depending upon whether $S$ has had an opportunity for previous stimulus familiarization training. Tests of the simple main effects of complexity and association value were performed and increases in stimulus complexity yielded a significant increase in recognition performance in the familiarization training condition $(F=4.44$, df $=$ $2 / 84, \mathrm{p}<.025)$.

The results suggest that: (a) familiarization training has a strong positive transfer effect upon subsequent recognition performance; (b) this effect is most marked with high complexity stimuli; and (c) the degree to which familiarization training facilitates recognition does not appear to be affected by the association value of the stimuli. Thus the results can be viewed as providing at least modest support for the differentiation position (Gibson \& Gibson, 1955). The greater facilitating effect of familiarization in the high stimulus complexity condition may be due to the fact that familiarization training in the present experiment allowed $S$ to view all of the stimulus variation within the set before learning and recognition tasks were performed. Further, when there is more information within a set of stimuli available for discrimination as is the case with higher levels of stimulus complexity, it appears that familiarization training has an even more marked positive transfer effect. Thus it is suggested that greater stimulus complexity may increase the amount of usable discrimination information in a stimulus set and that familiarization training allows $S$ to make use of this information.

\section{REFERENCES}

EGAN, J. P. Recognition memory and the operating characteristic. Indiana University, Hearing and Communication Laboratory, AFCRC TN 5851, AD-152650. June 15, 1958.

GARNER, W. R. Uncertainty and structure as psychological concepts. New York: John Wiley and Sons, Inc., 1966.

GIBSON, J. J., \& GIBSON, E. J. Perceptual learning: Differentiation or enrichment? Psychol. Rev., 1955, 62, 32-41.

GOSS, A. E. A stimulus-response analysis of the interaction of cue-producing and instrumental responses. Psychol. Rev., 1955, 62, 20-31.

GREEN, D., \& SWETS, J. A. Signal detection and psychophysics. New York: John Wiley and Sons, Inc., 1966.

POLLACK, I., NORMAN, D. A., \& GALANTER, E. An efficient nonparametric analysis of recognition memory. Psychon. Sci, 1964, 1, 327-328.

TIGHE, L. S., \& TIGHE, T. J. Discrimination learning: Two views in historical perspective. Psychol. Bull., 1966, 66, 353-370.

VANDERPLAS, J. M. \& GARVIN, E. A. The association value of random shapes. J. exp. Psychol, 1959, 57, 147-154. 